\title{
Comparison of Electrochemical Behaviors between FSW and MIG Joints for 6082 Aluminum Alloy
}

\author{
Peng Yong ${ }^{1}, \quad$ Shen Changbin ${ }^{1}, \quad$ Zhao Yadong $^{1,2}, \quad$ Chen Ying ${ }^{1}$ \\ ${ }^{1}$ Dalian Jiaotong University, Dalian 116028, China; ${ }^{2}$ Anyang Institute of Technology, Anyang 455000, China
}

\begin{abstract}
Electrochemical corrosion behaviors of friction stir welding (FSW) and MIG (mixed inert gas) welding joints of $6082 \mathrm{Al}$ alloy and parent material $6082 \mathrm{Al}$ alloy were investigated in a solution of $0.2 \mathrm{~mol} / \mathrm{L} \mathrm{NaHSO}{ }_{3}$ and $0.6 \mathrm{~mol} / \mathrm{L} \mathrm{NaCl}$, by potentiodynamic polarization curve, electrochemical impedance spectroscopy (EIS) and scanning electron microscopy (SEM) observation. Results show that the corrosion rate of the FSW joint is less than those of MIG joint and the parent material; the corrosion potential of the FSW joint is more positive than those of MIG joint and the parent material; the corrosion current density of the FSW joint is less than those of MIG joint and the parent material; the polarization resistance of the FSW joint is greater than those of MIG joint and the parent material. EIS Nyquist loops indicate that an inductive arc exist on the complex plane. SEM observation shows that a few shallow pits occurs on the surface of the FSW joint; however, a large number of deeper pits appear on the surface of the parent materials and MIG joint.
\end{abstract}

Key words: electrochemical behavior; friction stir welding; 6082 aluminum alloy; fusion welding

Friction stir welding (FSW) was invented at The Welding Institute (TWI) of UK in 1991 as a solid-state joining technique that unites thermal and mechanical aspects to produce a high quality joint, and it was initially applied to $\mathrm{Al}$ alloys ${ }^{[1]}$. During FSW process, the material undergoes intense plastic deformation at elevated temperature, resulting in generation of fine and equiaxed recrystallized grains. The fine microstructure in friction stir joints produces good mechanical properties. FSW is considered to be the most significant development in metal joining in two decades and is a 'green' technique due to its energy efficiency and environment friendliness compared to the conventional welding methods. Many researchers have devoted to systematically investigating the microstructural evolutions, the residual stress and hardness distributions, the mechanical properties strength and ductility of FSW joints; however the electrochemical corrosion behaviors and treatment to improve the corrosion resistance are studied relatively scarcely ${ }^{[2,3]}$. For a wide range of engineering applications of FSW, the corrosion susceptibility, especially the ambient electrochemical corrosion behavior of the FSW of high-strength aluminum is a concern. In the present work, in the ambient temperature solution of $0.2 \mathrm{~mol} / \mathrm{L} \mathrm{NaHSO}_{3}$ and $0.6 \mathrm{~mol} / \mathrm{L}$ $\mathrm{NaCl}$, the electrochemical corrosion behavior of friction stir and MIG welding joint of $6082 \mathrm{Al}$ alloy, and parent material were comparatively investigated by gravimetric test, potentiodynamic polarization curve, EIS, and SEM observation.

\section{Experiment}

Static mass loss experiments were carried out in a rectangular glass tanker with a capacity of $150 \mathrm{~mm} \times 20$ $\mathrm{mm} \times 10 \mathrm{~mm}$, which was airtight by a glass cover with some small holes to put the strings tied with the separate samples. The separate samples were suspended at the bottom of the tanker to ensure them fully immerse into the electrolyte. After the immersion tests for a given interval, the samples

Received date: February 01, 2016

Foundation item: Specialized Research Fund for the Doctoral Program of Higher Education of China (2013212412003); Liaoning Province Education Administration (2014185)

Corresponding author: Shen Changbin, Ph. D., Professor, School of Materials Science and Engineering, Dalian Jiaotong University, Dalian 116028, P. R. China, Tel: 0086-411-84106806,E-mail: shencb@djtu.edu.cn 
were dried and weighed by a type-FA1104A electrical balance (accuracy: $0.1 \mathrm{mg}$ ), and finally observed by SEM.

Potentiodynamic polarization tests were carried out using CHI600B electrochemical station at room temperature, using a pyrex glass, single compartment, three-electrode cell with a capacity of $100 \mathrm{~mL}$. Electrode potentials were measured with respect to an aqueous $\mathrm{KCl}$-saturated calomel electrode(SCE), with a Luggin probe positioned close to the electrode surface to minimize the ohmic potential drop. A Pt sheet was used as the counter electrode. The potential was scanned from $400 \mathrm{mV}$ to $-300 \mathrm{mV}$ versus the open current potential $E_{\text {ocp. }}$. Scanning speed was set at 0.166 $\mathrm{mV} / \mathrm{s}$. Before starting the polarization measurements, the electrode was immersed in the electrolyte until a steady free corrosion potential. At room temperature, using a pyrex glass, single compartment, and three-electrode cell with a capacity of $100 \mathrm{~mL}$, the EIS dispersions were recorded by a PARC Parstat-2273 system controlled by a personal computer via powersine software, the frequency range was from about $0.1 \mathrm{mHz}$ to $100 \mathrm{kHz}$ at open circuit potential. The amplitude of sinusoidal excitation voltage is $10 \mathrm{mV}$. Direct current potential is 0 volt versus open circuit potential. The fitted results (herein, double layer capacitance $C$, solution resistance $R_{\mathrm{s}}$, charge transfer resistance $R_{\mathrm{t}}$, reaction resistance $R_{0}$, polarization resistance $R_{\mathrm{p}}$ and inductive element $L$ ) of the equivalent circuits were obtained by Zsimpwin software.

The morphologies of corrosion surfaces for joints and parent metals after static mass loss experiment (gravimetric test) and polarization tests were analyzed by JSM-6360LV SEM.

The tests were carried on with 6082-T6 Al alloy plate in thickness of $8 \mathrm{~mm}$. The FSW samples were prepared by a piece of suspensory apparatus manufactured by China FSW Center. The process parameters were selected as the tool rotation rate $1200 \mathrm{r} / \mathrm{min}$, the traverse speed $200 \mathrm{~mm} / \mathrm{min}$.
The MIG samples were prepared by CNR Tangshan Railway Vehicle Co., Ltd. After prepared, all the samples including FSW and MIG were ground in order to get rid of the surface fault, and then longitudinally cut into 18 $\mathrm{mm} \times 18 \mathrm{~mm}$ sheets along the joints by a wire saw.

All chemicals used were of the purity of reagent grade. Each wire-cut sample was encapsulated with epoxy resin and supported by a PVC holder, then ground with grit silicon carbide ( $\mathrm{SiC}$ ) paper, and finally polished by diamond paste. The exposure area of the sample was 10 $\mathrm{mm} \times 10 \mathrm{~mm}$.

\section{Results and Discussion}

\subsection{Static mass loss experiments}

Immersion tests of $6082 \mathrm{Al}$ alloy and its joint in 0.2 $\mathrm{mol} / \mathrm{L} \mathrm{NaHSO}_{3}$ and $0.6 \mathrm{~mol} / \mathrm{L} \mathrm{NaCl}$ solution can be reliable for the determination of its average corrosion rate because the corrosion process of $\mathrm{Al}$ alloy is active dissolution. Herein, $0.2 \mathrm{~mol} / \mathrm{L} \mathrm{NaHSO}_{3}$ and $0.6 \mathrm{~mol} / \mathrm{L} \mathrm{NaCl}$ solution was picked up as the corrosive media in order to simulate the polluted acidic industrial atmosphere. For each kind of material (FSW joint and 6082 parent material), there are three parallel samples. The average corrosion rate was calculated by Eq.1, and all data for immersion tests are listed in Table 1.

$$
v=\frac{m_{0}-m_{1}}{s t}
$$

Where $m_{0}$ and $m_{1}$ are the sample mass before and after corrosion, respectively, $s$ is the area exposed in solution, $t$ is the time of corrosion, $v$ is corrosion rate of each measurement, and $\bar{v}$ is average corrosion rate of three parallel samples. From Table 1, the average corrosion rate $\bar{v}$ of FSW joint, MIG joint and parent metal is 2.39, 4.6 and $3.8 \mathrm{~g} / \mathrm{m}^{2} \cdot \mathrm{h}$, respectively. The results demonstrate that the corrosion resistance of FSW joint is improved, in comparison with that of MIG joint and $6082 \mathrm{Al}$ alloy.

Table 1 Results of immersion test in $0.2 \mathrm{~mol} / \mathrm{L} \mathrm{NaHSO}_{3}+0.6 \mathrm{~mol} / \mathrm{L} \mathrm{NaCl}$ solution

\begin{tabular}{|c|c|c|c|c|c|c|}
\hline Sample & $s / \times 10^{-6} \mathrm{~m}^{2}$ & $m_{0} / g$ & $m_{1} / g$ & $t / \mathrm{h}$ & $v / \times 10^{-1} \mathrm{~g} \cdot\left(\mathrm{m}^{2} \cdot \mathrm{h}\right)^{-1}$ & $\bar{v} / \times 10^{-1} \mathrm{~g} \cdot\left(\mathrm{m}^{2} \cdot \mathrm{h}\right)^{-1}$ \\
\hline \multirow{3}{*}{ FSW } & 1160 & 6.5198 & 6.5124 & 24 & 2.66 & \multirow{3}{*}{2.39} \\
\hline & 1160 & 6.5225 & 6.5162 & 24 & 2.26 & \\
\hline & 1160 & 6.4463 & 6.4346 & 24 & 2.26 & \\
\hline \multirow{3}{*}{ MIG } & 708 & 3.1911 & 3.1839 & 24 & 4.24 & \multirow{3}{*}{4.6} \\
\hline & 699 & 3.1022 & 3.0951 & 24 & 4.23 & \\
\hline & 728 & 3.3455 & 3.3378 & 24 & 4.41 & \\
\hline \multirow{3}{*}{$6082 \mathrm{Al}$ alloy } & 1160 & 6.4525 & 6.4420 & 24 & 3.88 & \multirow{3}{*}{3.8} \\
\hline & 1160 & 6.4525 & 6.4418 & 24 & 3.84 & \\
\hline & 1188 & 6.6798 & 6.6702 & 24 & 3.37 & \\
\hline
\end{tabular}


The main reason may be related to the microstructure difference between them. During FSW process, the material undergoes intense plastic deformation at elevated temperature; fine and equiaxed crystallized grains are subsequently generated $^{[3]}$. The fine microstructure in friction stir joints produces good mechanical properties. After intense plastic deformation, the pronounced physical irregularities are reduced and chemically homogenous; meanwhile, parent metal substrate consisting of dense tangles of dislocations is considerably reduced by recrystallization in the joint zone. All the beneficial factors overcome the negative effect caused by the residual stress, thus localized attack microcells are not easy to occur in the joint surface, and then FSW joint gets more resistance to the aggression of $\mathrm{HSO}_{3}{ }^{-}$and $\mathrm{Cl}^{-}$ion. For MIG joint, with the addition of solder and input of thermal energy accompanied with the process, the resistance to the electrochemical corrosion is remarkably reduced, even worse than that of the parent metal.

\subsection{Potentiodynamic polarization curves}

Fig. 1 is the potentiodynamic polarization curves of the FSW and MIG of $6082 \mathrm{Al}$ alloy and parent metal in 0.2 $\mathrm{mol} / \mathrm{L} \quad \mathrm{NaHSO}_{3}+0.6 \mathrm{~mol} / \mathrm{L} \mathrm{NaCl}$ solution at ambient temperature. The electrochemical parameters of FSW and MIG joint of $6082 \mathrm{Al}$ alloy and the parent material are listed in Table 2. From Fig.1 and Table 2, the corrosion potential $E_{\text {corr }}$ of the FSW joint $(-559.85 \mathrm{mV})$ is more positive than those of the parent material and MIG joint (-601.89, -685.11 $\mathrm{mV}$ respectively), while the corrosion current density $I_{\text {corr }}$ of the FSW joint $\left(0.26 \mu \mathrm{A} \cdot \mathrm{cm}^{-2}\right)$ is less than those of the parent material and MIG joint $(0.62,1.45$ $\mu \mathrm{A} \cdot \mathrm{cm}^{-2}$, respectively). The results demonstrate that the corrosion resistance of FSW joint is improved, in comparison with that of MIG joint and $6082 \mathrm{Al}$ alloy, which are in accordance with the results of static mass loss experiments.

During the immersion period, $\mathrm{HSO}_{3}{ }^{-}$would be dissociated, then be oxidized by the oxygen in the air, and finally $\mathrm{SO}_{4}{ }^{2-}$ ion can be gotten in the solution which is the main corrosive radical for $\mathrm{Al}$ alloy. The reaction process can be described by Eeqs.(2) (4) as follows ${ }^{[4]}$ :

$$
\begin{aligned}
& \mathrm{HSO}_{3}^{-} \leftrightarrow \mathrm{SO}_{3}^{2-}+\mathrm{H}^{+} \quad K=1.05 \times 10^{-2} \\
& \mathrm{HSO}_{3}^{-}+\frac{1}{2} \mathrm{O}_{2} \leftrightarrow \mathrm{HSO}_{4}^{-} \\
& \mathrm{HSO}_{4}^{-} \leftrightarrow \mathrm{SO}_{4}^{2-}+\mathrm{H}^{+} \quad K=1.05 \times 10^{-2}
\end{aligned}
$$

The cathode reaction is mainly a hydrogen evolution process; the reaction can be simply described by Eq.(5) as follows:

$$
2 \mathrm{H}^{+}+2 \mathrm{e} \rightarrow \mathrm{H}_{2} \uparrow
$$

The overall process rate is determined by anodic

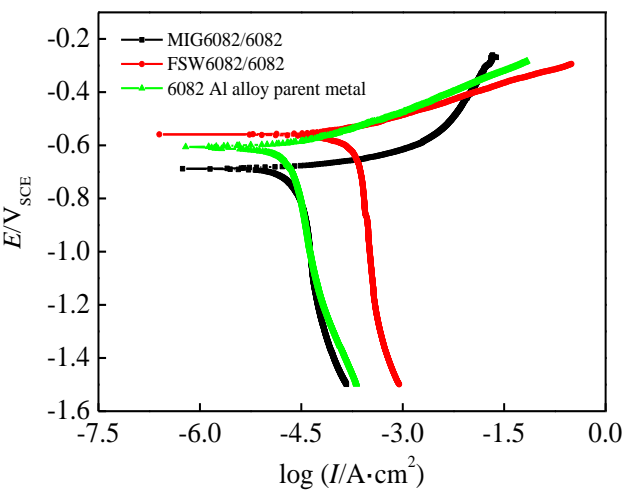

Fig.1 Potentiodynamic polarization curves

polarization. The obstacle for the anodic solution is attributed to the passage, along which $\mathrm{Al}^{3+}$, spalled from the metal lattice, overcomes the oxide film barrier and approaches the oxide film/solution interface. In the mixed solution, $\mathrm{Cl}^{-}$is absorbed on the surface of some active sites such as crystal boundaries, impurities to accelerate localized attack; this is called a synergistic effect.

\subsection{SEM analysis}

Fig.2a 2c are the SEM morphologies for FSW and MIG joints and $6082 \mathrm{Al}$ alloy parent metal. The morphology of FSW joint after room temperature static immersion test is relatively even, revealing the classical formation of the elliptical 'onion' structure in the center of joint, which are a characteristic of the FSW joint, the pits are nearly uniform, and no visible superficial porosity or macroscopic defects exist, which indicates that localized attack for FSW joint in the given media can be neglected. For MIG joint and 6082 $\mathrm{Al}$ alloy parent metal, the morphologies are relatively rough, the pitting gets worse, and some deep pits can be obviously observed; so the MIG joints and $6082 \mathrm{Al}$ alloy parent metal can be easily attacked by $\mathrm{Cl}^{-}$ion, which is a classical anion causing severe local pits. The localized attacks of MIG joint and $6082 \mathrm{Al}$ alloy parent metal are supposed to result from the microcells due to the influx impurity and chemical nonhomogenization.

\subsection{EIS analysis}

Fig.3 is the Nyquist plots of FSW and MIG joints of 6082 $\mathrm{Al}$ alloy and parent material. Fig. 4 is the equivalent circuit. The electrochemical parameters are also listed in Table 2.

EIS is a versatile and useful tool for studying mechanisms of electrode processes. It is a transient technique of linear systems applied to the electrode processes in the steady-state. From Fig.3, an inductive loop has been observed in the Nyquist plots. The equivalent circuit consists of three kinds of linear electric elements, namely, the charge transfer 


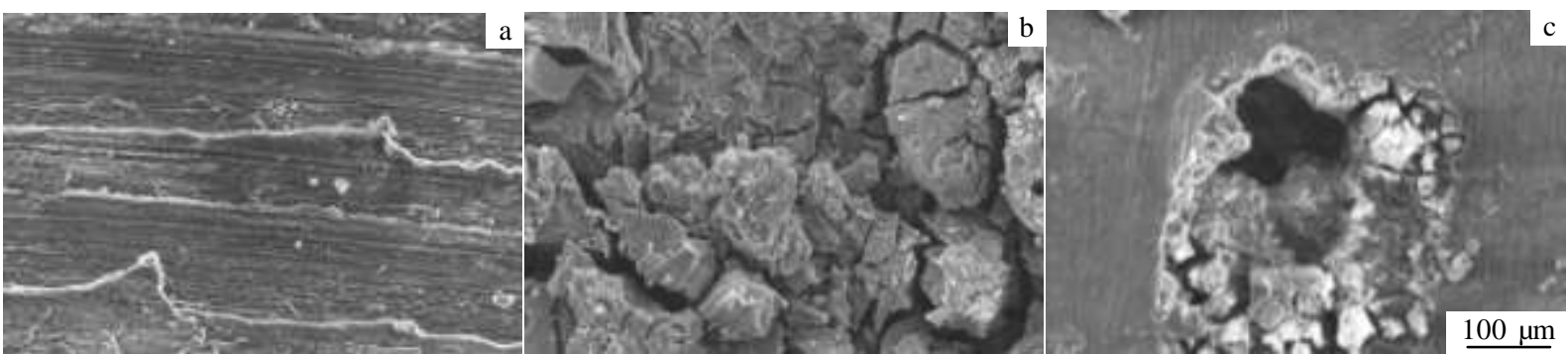

Fig.2 SEM morphologies: (a) FSW joint, (b) MIG joint, and (c) $6082 \mathrm{Al}$ alloy

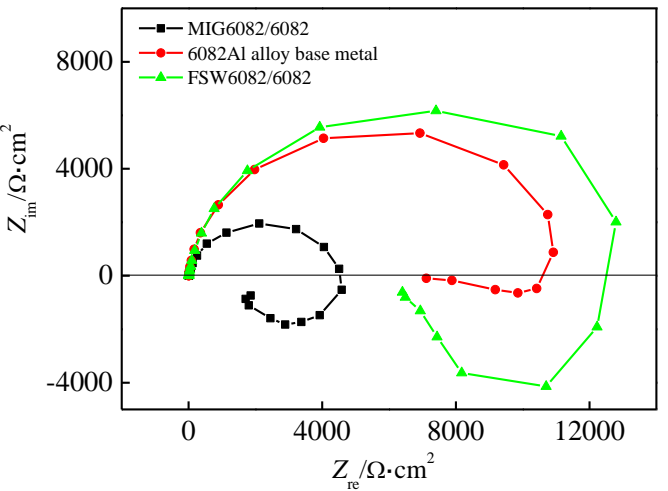

Fig.3 Nyquist plots

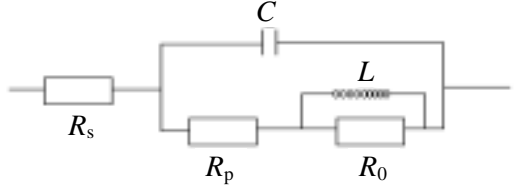

Fig.4 Equivalent circuit resistance, the electrode double-layer capacitance $\mathrm{C}$, and inductor L. Often the EIS data are of a peculiar shape and cannot be fit to any of the existing models. Therefore, it is necessary to evaluate methods which can be used to determine whether the experimental data meet the requirements for real impedance data. In addition, the data need to be finite in the frequency range between infinity and zero. From Fig.3, all the impedance spectra are composed of one capacitive loop in the first quadrant at high frequency and one inductive in the fourth quadrant at the lowest frequency. It indicates a similar reaction mechanism; this type of impedance plot could be interpreted by a model similar to the Bockris mechanism ${ }^{[5]}$. From Fig. 4 and table 2, the polarization resistance $R_{\mathrm{p}}$ of the FSW joint $\left(3696 \Omega \cdot \mathrm{cm}^{2}\right)$ is greater than those of MIG joint and the parent material $\left(901.9 \Omega \cdot \mathrm{cm}^{2}, 1556 \Omega \cdot \mathrm{cm}^{2}\right.$ respectively). The results demonstrate that the corrosion resistance of FSW joint is improved, in comparison with that of MIG joint and $6082 \mathrm{Al}$ alloy, which are in accordance with the results of static mass loss experiments and potentiodynamic polarization curves.

Table 2 Electrochemical parameters

\begin{tabular}{ccccccc}
\hline Sample & $E_{\text {corr }} / \mathrm{mV}_{\text {SCE }}$ & $I_{\text {corr }} / \mu \mathrm{A} \cdot \mathrm{cm}^{-2}$ & $R_{\mathrm{s}} / \Omega \cdot \mathrm{cm}^{2}$ & $R_{\mathrm{p}} / \Omega \cdot \mathrm{cm}^{2}$ & $R_{0} / \Omega \cdot \mathrm{cm}^{2}$ & $C / \mu \mathrm{F} \cdot \mathrm{cm}^{2}$ \\
\hline FSW & -559.85 & 0.26 & 7.597 & 3696 & 2443 & 6.3 \\
MIG & -685.11 & 1.45 & 6.852 & 901.9 & 1322 & 12.6 \\
6082 Al alloy & -601.89 & 0.62 & 8.7 & 1556 & 2941 & 6.5 \\
\hline
\end{tabular}

After FSW, the rolling direction of the parent metal is thoroughly disrupted, and the dense tangles of dislocations of the $6082 \mathrm{Al}$ alloy base metal are considerably reduced by recrystallization in the joint zone; the above factors enhance the ability to resist the aggression of $\mathrm{Cl}^{-}$ion in the room temperature aqueous solution.

\section{Conclusions}

1) The corrosion rate of the FSW joint is less than those of the parent material and MIG joint; the corrosion potential of the FSW joint is more positive than those of the parent material and MIG joint; the corrosion current density is less than those of the parent material and MIG joint.

2) An inductive arc exists on all the complex planes.

3) A few shallow pits appear on the surface of the FSW joint; however, a large number of deeper pits occur on the surface of the parent material and MIG joint.

\section{References}

1 Leitão C, Louro R, Rodrigues D M. Materials and Design[J], 
2012, 37: 402

2 Ferrer K S, Kelly R G. Corrosion[J], 2001, 57(2): 110

3 Corral J, Trillo E A, Ying L et al. Journal of Materials Science Letters[J], 2000, 19: 2117
4 Mishra R S, Ma Z Y. Materials Science and Engineering R[J], 2005, 50: 1

5 Shen C B, Wang S G, Yang H Y et al. Corrosion Science [J], 2006, 48: 1655

\title{
6082 铝合金摩擦摚拌焊缝和熔化极惰性气体保护焊缝电化学性能对比
}

\author{
彭 勇 ${ }^{1}$, 沈长斌 ${ }^{1}$, 赵亚东 ${ }^{1,2}$, 陈 影 $^{1}$ \\ (1. 大连交通大学, 辽宁 大连 116028) \\ (2. 安阳工学院, 河南 安阳 455000)
}

\begin{abstract}
摘 要: 利用动电位极化曲线, 交流阻抗谱(EIS) 和扫描电子显微镜(SEM)测试方法, 在室温 $0.2 \mathrm{~mol} / \mathrm{L} \mathrm{NaHSO}$ 和 $0.6 \mathrm{~mol} / \mathrm{L} \mathrm{NaCl}$ 的水溶 液中, 对比研究了铝合金搅拌摩擦焊(FSW)焊缝和熔化极惰性气体保护焊(MIG)焊缝电化学性能。结果表明: FSW焊缝的腐蚀速率低于 MIG焊缝和母材的腐蚀速率; FSW焊缝的腐蚀电位高于MIG焊缝和母材的腐蚀电位; FSW焊缝的腐蚀电流密度低于MIG焊缝和母材的腐 蚀电流密度; FSW焊缝的极化电阻高于MIG焊缝和母材的极化电阻。所有样品的EIS Nyquist 谱图上均有一感抗弧存在; SEM观察表明: 仅有少量浅蚀坑出现在FSW焊缝表面。
\end{abstract}

关键词: 电化学行为; 搅拌摩擦焊; 6082 铝合金; 熔化焊

作者简介: 彭 勇, 男, 1989 年生, 硕士, 大连交通大学材料科学与工程学院, 辽宁 大连 116028, 电话: 0411-84106806, E-mail: shencb@djtu.edu.cn 